\title{
CrimRxiv
}

\section{Review 2 of "Defense,}

disrespect, and \#deadly: A qualitative exploration of precursors to youth violence informed through hospital-based violence prevention program follow up"

Scott Decker

Published on: Jun 21, 2021

License: Creative Commons Attribution 4.0 International License (CC-BY 4.0). 
Vote: Publish pending minor changes

[For votes to count, referees must reasonably explain why they voted as they did. Thus, please explain your vote. If you voted to publish pending minor changes, specify each change, why it is needed, and, possibly, how it should/could be done.]

This paper is well-developed. That is to say, it is strong conceptualization of a problem of importance to the field. There is sufficient attention to methods, without going overboard as is sometimes the case. There is a growing body of literature on the use of social media for non-legal purposes and violence is at the top of that list. There are lots of "threats" on the web, but little in the way of efforts to link online to actual threats. The work in this area is characterized by small, opportunistic samples which seems appropriate at this stage of development of the issue. Web activity is depicted often as individual but there is a group context, particularly as gangs and other criminallyinvolved groups are engaged in using the web for purposes that often include violence. The authors may want to see the Moule, et al article noted below as it integrates organizational theory into the issue.

Paper is well written and organized. Generally good job on the literature.

How are the second and third themes distinguished form each other? What is disrespect toward a social media platform? Develop this a bit further as it appears to be a new concept introduced to online threats, etc.

What is "the Midlands"? Is it the "midwestern city"? Why not name the city?

A bit more detail about Dedoose would be welcomed for readers unfamiliar but interested.

Disrespect is a common theme in studies of youth violence? How is online disrespect different from in person disrespect?

Keep the focus. The paper is about qualitative threats through online venues. Or is it about a youth violence prevention program? Or is it...

Lots of good material here. I would like to see the authors make more of their data.

Moule, Richard K., David C. Pyrooz and Scott H. Decker. 2017. Internet Adoption and Online Behavior among American Street Gangs: Integrating Gangs and Organizational 
CrimRxiv Review 2 of "Defense, disrespect, and \#deadly: A qualitative exploration of precursors to youth violence informed through hospital-based violence prevention program follow up

Theory. British Journal of Criminology, 54, 6, 1186-1206. 